\title{
PRODUÇÃO DESTRUTIVA E ESTADO CAPITALISTA
}

Por: Demetrio Cherobini

MÉSZÁROS, István. Produção destrutiva e Estado capitalista. São Paulo: Ensaio, 1989. $105 \mathrm{p}$.

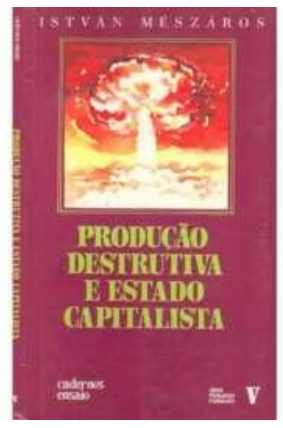

A teoria da crise estrutural do capital, de István Mészáros, despertou polêmica entre os estudiosos marxistas por se contrapor a algumas leituras consolidadas entre essa destacada tradição intelectual e política. Até aí, nenhum problema, visto que o confronto franco e aberto de ideias fecunda a discussão e estimula a produção do conhecimento, condição imprescindível para a efetivação plena e consequente daquilo que Marx chamou de emancipação humana. No entanto, observamos que algumas imprecisões em relação à avaliação da formulação mészáriana têm levado ao truncamento do debate, o que implica em barreiras consideráveis para que a polêmica se torne frutífera e concorra positivamente para o avanço dos esforços políticos daqueles que, na atualidade, se situam do lado proletário da luta de classes. Nesse sentido, acreditamos que uma leitura atenta do ensaio Produção destrutiva e Estado capitalista ajuda a dirimir boa parte dessas imprecisões.

0 referido ensaio, aparecido no Brasil em 1989, analisa temas fundamentais, mais tarde amplamente desenvolvidos no principal livro de Mészáros, Para além do capital: rumo a uma teoria da transição, de 1995. Não por acaso, as reflexões contidas em Produção destrutiva e Estado capitalista foram inseridas no interior dessa obra maior e, por tal razão, revelam, sob a luz privilegiada do presente, elementos importantes do amadurecer da elaboração do filósofo a respeito do sistema do capital e sua crise estrutural. 
Qual o $x$ da questão? Em nossa opinião, há duas posições problemáticas. De um lado estão os leitores que acreditam que a teoria da crise estrutural designaria uma época histórica, iniciada em torno de 1970, a partir da qual o desenvolvimento das forças produtivas se mostraria difícil, ou até mesmo impossível ${ }^{1}$. De outro lado aparecem os críticos segundo os quais a referida teoria seria incapaz de apreender a verdadeira dinâmica do capital, o que redundaria numa negação das célebres crises cíclicas², analisadas por Marx em sua obra de maturidade. Para nós, nenhuma dessas leituras se sustenta, como procuraremos demonstrar, sinteticamente, com base na argumentação apresentada em Produção destrutiva e Estado capitalista.

A premissa de que Mészáros aí parte é a da relação dialética existente entre produção e consumo no sistema do capital. Haveria, segundo o filósofo, uma determinação recíproca, envolvendo inúmeras mediações, atuando em ambos os polos dessa relação, sendo que o momento predominante caberia ao da produção (ou melhor, da reprodução) do capital.

Nesse contexto, é possível perceber que a assim chamada crise estrutural tem a ver com aquilo que Meszáros chama de produção destrutiva - ou como José Chasin (prefaciador do ensaio) diz: a produção da destruição -, que responde por uma conformação específica do movimento dialético que percorre produção e consumo. A produção destrutiva seria um meio desenvolvido pelo próprio capital para lidar com as contradições inerentes ao processo de superprodução (ou superprodução crônica, como o pensador húngaro a nomeia em algum ponto de seu texto).

Para delinear tais ideias, Mészáros lança mão de uma categoria que precisa ser entendida no contexto da sua argumentação, articulada com suas premissas e com as demais formulações aí desenvolvidos: a taxa de uso decrescente, que diz respeito, entre outras coisas, à quantidade proporcional de tempo alocado na produção de bens relativamente duráveis e de bens de consumo rápido. A taxa de uso decrescente, ou melhor, a forma como o capital manipula a taxa de uso decrescente - e ressaltemos que Mészáros compreende essa taxa como um fruto do próprio desenvolvimento da força produtiva do trabalho -, é fundamental para a definição do conceito de crise estrutural.

\footnotetext{
${ }^{1}$ Esta é a posição de Sérgio Lessa. Ver LESSA, Sérgio. Alienação e estranhamento. Apêndice a MARX, Karl. Cadernos de Paris; Manuscritos econômico-filosóficos. São Paulo: Expressão Popular, 2015.

${ }^{2}$ Esta é a posição de José Martins. Ver MARTINS, José. Império do terror: Estados Unidos, ciclos econômicos e guerras no início do século XXI. São Paulo: Editora Instituto José Luís e Rosa Sundermann, 2005.
} 
A taxa de uso decrescente, no interior da crise estrutural, não tem a ver exatamente com um "não uso" (embora isso possa ocorrer) da produção social, mas com algo mais específico: um uso dissipador (ou destrutivo) da mesma. Isso incide não só sobre os bens de consumo rápido ou os bens relativamente duráveis, mas em todas as relações sociais que formam o circuito incessante da autorreprodução do capital.

Mészáros explica que, para esse sistema, é indiferente se os sujeitos utilizam muito ou pouco, ou mesmo se utilizam, as mercadorias que são trazidas à luz no processo produtivo e vendidas na sequência. No entanto, a linha de menor resistência que o capital acabará adotando se definirá pela implementação do uso dissipador, visto que tal forma, nas condições atuais, é a que revela ser a mais adequada ao seu processo de reprodução sociometabólica. (Observamos, assim, que, de acordo com o filósofo húngaro, o processo de produção e reprodução do capital cria, em cada momento histórico, um tipo específico de uso, adaptado às suas necessidades).

$\mathrm{Na}$ atual época, tal processo se corporifica na combinação de superprodução e subutilização de capital, mas, sublinhamos, superprodução e subutilização no sentido dissipador, isto é, destrutivo, como mencionamos acima. Isso se verifica, articuladamente, nas mais variadas esferas do sistema, criando, entre outras coisas, força de trabalho supérflua, sucateamento de meios de produção, obsolescência planejada e o surgimento do complexo militar-industrial, o elemento mais importante para a apreensão da teoria da crise estrutural. De acordo com Mészáros, no contexto de tal crise, o complexo militar-industrial se estabelece como centro que organiza a dinâmica sociometabólica do capital.

O complexo militar-industrial, em forma institucionalizada, é eficaz em resolver o problema do imperativo radical de dissipação em larga escala de "bens perfeitamente usáveis", assim como do próprio capital. 0 sistema efetua, desse modo, uma "estratégia de realização" que não depende da demanda flutuante do mercado e não se atrela às limitações do valor de uso assentado sobre alguma necessidade que se possa considerar como verdadeiramente humana.

Daí Mészáros afirmar: “o objetivo e o princípio orientador da produção vem a ser: como assegurar a máxima expansão possível (e a correspondente lucratividade) na base de uma taxa de uso mínima, que mantenha a continuidade da reprodução ampliada?" - frisemos, aqui, os seguintes termos: produção, expansão, lucratividade e reprodução ampliada: em nossa opinião, é essa a passagem que melhor permite 
descartar a interpretação de que a teoria da crise estrutural se definiria pela dificuldade ou ausência de desenvolvimento das forças produtivas.

Sob tais condições, diz o filósofo húngaro, verifica-se a "transformação radical da produção genuinamente orientada para o consumo em destruição". Realiza-se, consequentemente, de maneira generalizada, um "crescimento cancerígeno", uma "produção-dissipadora", que adota uma forma extremada de desperdício, "isto é, a destruição direta de vastas quantidades de riqueza acumulada e de recursos elaborados como meio dominante de ordenação do capital superproduzido". Nesse contexto, consumo e destruição se tornam equivalentes funcionais. 0 capital se realiza, assim, na destruição.

Mészáros retoma, aqui, a reflexão estabelecida anteriormente por Rosa Luxemburgo sobre a produção-militarista, mas diz que o que se verifica hoje é algo mais ricamente determinado, justamente o complexo militar-industrial, cuja complexidade é dada pela relação íntima e visceral que tal sistema mantém com o Estado capitalista. Nesse sentido, o filósofo ressalta que, depois do segundo pósguerra, as transformações das estruturas produtivas, realinhadas paralelamente com o Estado, fizeram com que "a própria Nação" corporificasse em si uma fusão de produtor/comprador/consumidor, política e ideologicamente legitimada, adequada às necessidades expansivas do sociometabolismo do capital.

Nesse contexto, a posição e as ações econômicas e políticas dos EUA desempenham um papel-chave para a definição da crise estrutural, na medida em que esse país se constituiu, em razão das circunstâncias históricas, como o centro do sistema mundial do capital. Assim, segundo Mészáros, apesar de o complexo militarindustrial já ser algo em progressão no início do século XX, a sua adoção geral só aconteceu depois da Segunda Guerra Mundial, sendo os EUA o lócus onde esse sistema exerce, desde então, a posição dominante. É aí que se situa a etapa mais desenvolvida do fenômeno em questão, a materialização consumada da fusão entre a dinâmica produtivo-destrutiva do capital e a Nação produtora/compradora/consumidora do complexo militar-industrial, fato que, por certo, desencadeia consequências graves para todo o planeta.

Cabe, agora, a pergunta: esse quadro, de crise estrutural, elimina a teoria das crises cíclicas? De forma alguma, e aqui chegamos ao ponto, talvez, mais importante da reflexão de Mészáros: aquilo que o autor chama de continuum depressivo, que nada tem a ver com o estancamento ou a não retomada da superprodução de capital, nem com o não desenvolvimento das forças produtivas, e sim com a combinação de 
administração das crises e autorreprodução destrutiva do capital, no sentido que acima expusemos.

Mészáros diz que, no contexto da autorreprodução destrutiva do capital, as crises não são eliminadas, mas "administradas" (isto é, produzidas e manipuladas intencionalmente) e "estendidas", "tanto no sentido temporal, como no que diz respeito à sua localização estrutural no conjunto global". E complementa afirmando que, enquanto o capital e seu Estado tiverem sucesso na imposição de seus interesses, a tendência é de que "não haverá grandes tempestades [isto é, como a crise de 1929] a intervalos razoavelmente distantes, mas precipitações [isto é, crises cíclicas e periódicas] de frequência e intensidade crescentes por todo lugar".

Portanto, podemos verificar que o conceito de crise estrutural não só não elimina o conceito de crise cíclica, como o engloba. Com efeito, Mészáros afirmou, mais tarde, quando da ocasião da crise econômica de 2008, o seguinte:

\begin{abstract}
Capitalismo e crise são sinônimos. Marx disse isso muitas vezes. Mas ele estava a falar acerca de crises cíclicas. 0 capitalismo tem crises regularmente. Marx utilizou mesmo a expressão: estas crises descarregam-se numa tempestade. Então estamos de volta ao normal, por assim dizer. Um bocado de capital excedente é destruído, e pode-se começar todo o jogo outra vez, até que se atinja um ponto de superacumulação, e então uma nova descarga torna-se necessária. É isto que temos estado a viver. Agora, o nosso grande privilégio, se se quiser, é que temos ambas. Temos tanto a crise cíclica, como esta profunda e sempre em aprofundamento crise estrutural de todo o sistema, o sistema total do capital (Cf. MÉSZÁROS, 2017).
\end{abstract}

Vemos, assim, de modo conclusivo, que Mészáros não está negando a teoria das crises cíclicas (com sua correspondente "destruição produtiva"), mas integrando-a dialeticamente à teoria da crise estrutural (e a sua consequente produção destrutiva).

Atentemos, apenas, para a grande novidade da coisa: enquanto que nas crises cíclicas, materializadas no ponto mais alto do ciclo da superprodução de capital, a destruição se manifestava como meio para a renovação e retomada de todo o processo, no contexto da crise estrutural (que não elimina, como mostramos, as crises cíclicas, mas que se serve delas), sob o domínio da produção destrutiva e a afirmação radical do complexo militar-industrial, a destruição não representa a saída da crise, mas a própria locomotiva devastadora e impiedosa da dinâmica de reprodução sociometabólica do capital.

Com tal formulação, Mészáros se inscreve na melhor tradição revolucionária marxista, aquela que se empenha em criar novos conceitos e categorias, com o objetivo de apreender a realidade concreta para enfrentá-la e superá-la. A criação de 
novos conceitos e categorias (e não somente a repetição dos antigos), para fins práticos de transformação do mundo, foi algo primado por Marx, e não faria sentido imaginar que o filósofo de Trier pretendesse que não adotássemos a mesma postura intelectual e política para o enfrentamento da ordem do capital.

\section{Referências}

MÉSZÁROS, István. Crise dual. Londres: 2008. Disponível em <http://resistir.info/meszaros/dual crisis.html>. Acesso em 09/11/2017.

Produção destrutiva e Estado capitalista. São Paulo: Ensaio, 1989. 105 p.

Recebido em 19/11/2017

Aprovado em 03/08/2018 